\title{
Precisiones iconográficas en torno a dos piezas de las Alhajas del Delfín
}

\author{
Mario lópez-Barrajón Barrios *
}

A. J. y M. V.

La fabulosa colección denominada "Alhajas del Delfin", que hoy expone el Museo del Prado, forma parte de la herencia que en 1712 Felipe $\checkmark$ recibe, tras la muerte de su padre, heredero a la Corona francesa. Agrupa una serie de objetos de gran interés gemológico y artistico. Sus materiales; ágatas, lapislázulis, diaspros, cristal de roca, delicadamente tallados, están guarnecidos por ricas labores de la mejor orfebrería de los siglos XVI y XVII. Tipológicamente son piezas de una lujosa vajilla en las que el valor ornamental supera con creces al funcional, ya por su forma, ya por su decoración a base de motivos vegetales y animales, frecuentes en otras obras de la época. Aparecen también escenas mitológicas esculpidas en los vasos de cristal de roca y en los numerosos camafeos que adornan varias de las cajas que posee la colección.

No podemos hablar de un programa iconográfico definido aunque los asuntos tallados a veces parecen referirse a la posible función del objeto. Abundan sobre todo temas marinos y también los relacionados con el vino, y como única excepción un tema bíblico: "Moises y la Roca de Horeb".

Para el presente estudio he elegido dos piezas cuyo tratamiento iconográfico es excepcional. La primera describe un asunto mitológico extraído fielmente de una fuente clásica y la segunda presenta un contenido

* Biblioteca de Ciencias Sociales de la UNED.

llustraciones:

Dibujos de las figuras 1, 2, 3, 5 y 6 realizados por Maria José Mendoza Traba (tomados de las fotografías publicadas en el Catálogo de las Alhajas del Delfín, Museo del Prado, Madrid, 1989). 
alegórico obtenido en la literatura artística del momento. Ambas están protagonizadas por personajes miticos y se suman a las corrientes artisticas y eruditas post-renacentistas fascinadas por las posibilidades estéticas, filosóficas y literarias que ofrece el Olimpo y sus "habitantes".

"La fuente de los doce Cesares», realizada en cristal de roca y datada hacia $1580^{\prime}$, es de las pocas piezas de la colección que aparece decorada con una historia completa. Condicionada por su forma ovalada, presenta tres niveles ornamentales: en el centro una lucha de centauros, tritones y ninfas, en el borde, rodeados de rica guarnición en oro y aljófar, doce camafeos de lapislázuli que representan doce Césares ${ }^{2}$, y entre estos dos niveles se desarrollan seis escenas de clara filiación mitológica identificadas por Diego Angulo ${ }^{3}$ :

«... Desarrolla la escena mitológica de un cazador, que armado de lanza y precedido de amorcillo, sale al campo y encuentra a una ninfa en el baño. Júpiter y Juno se aparecen a los dos personajes. Siguen la entrevista de Mercurio y la ninfa bajo el árbol y el grupo de gracias con el recién nacido...".

Podemos hablar de cierta imprecisión al analizar la escena y con el fin de solucionarlo hemos acudido al análisis de los inventarios ${ }^{4}$ que de las "Alhajas" se realizan en 1776, a las notas de 1815 de la Embajada Española en Paris y a las Observaciones de 1839 de la Junta Gubernativa del Museo de Ciencias Naturales. Los dos primeros documentos aportan sobre todo análisis del estado de las piezas y descripciones físicas. Sólo las observaciones de la Junta precisan algo más acerca del asunto representado:

«...Ofrecen varios grupos y son: un Mercurio y una ninfa sentados debajo de un árbol: un Cupido volando y un cazador que parece perseguirle: un cuerpo con dos cabezas, una de mujer y otra de hombre, y tres ninfas con un niño en los brazos de una de ellas. Hay además ciudades, torres, aves y otros animales que forman el paisaje...".

\footnotetext{
' Angulo Íniguez, D., Catálogo de las alhajas del Deltin, Madrid. Museo del Prado, 1989, pág. 132.

Op. cit., pág. 133. Angulo explica el uso de camafeos de Césares romanos en la decoración de una fuente similar del siglo xvil procedente de Austria y de otras piezas en el Louvre. Aporta reseñas bibliográficas sobre el empleo de series de emperadores romanos en el arte del Renacimiento.

Op. cit., pág. 132.

`Op. cit., págs. 234-235.
} 
Parece evidente la fuente consultada por D. Angulo, que además ofrece otros datos que pueden ayudar a precisar más exactamente el asunto descrito: "La historia de Hermafrodito", extraida fielmente de las narraciones de Ovidio conocidas como «Metamorfosis». Variando el tradicional orden dado a las escenas de la fuente nos encontramos con la representación minuciosa del episodio ${ }^{5}$ tallada en el cristal: Mercurio aparece sentado junto a una figura femenina. Este dios, en griego Hermes, ha gozado de los favores de muchas ninfas y diosas, entre ellas la del amor y la belleza: Venus, en griego Afrodita (fig. 1). A continuación aparece un grupo de tres mujeres sosteniendo un niño (fig. 2). Según Ovidio las ninfas cuidaron del hijo de estos dioses que estaba dotado de las "gracias y bellezas de su madre y de los ardides y talentos de su padre" ${ }^{6}$ por lo que fue llamado tomando el nombre de los dos. En la siguiente escena aparecen fondos de ciudad y un personaje con lanza precedido de Cupido (fig. 3). Volviendo a la narración, Hermafrodito abandona a sus protectores para viajar a los montes visitando las ciudades de Licia y los pueblos de Caria, donde encuentra una fuente en la que se para a descansar, siendo sorprendido por la ninfa que habitaba en sus aguas, Salmacis, que al instante se enamora del joven. En la decoración de esta escena, se representa ai muchacho sentado junto a un árbol frente a una figura femenina vestida únicamente con un velo. Para finalizar, una figura sumergida hasta la cintura, con un solo cuerpo y dos cabezas, tal como describen las Observaciones de 1839, alza sus brazos al Cielo donde las nubes rodean a dos dioses. La ninfa Salmacis en las "Metamorfosis" se aferra al cuerpo de Hermafrodito pidiendo a los dioses no separarse de él jamás, favor que le es concedido, entrelazándose sus cuerpos en uno solo con atributos femeninos y masculinos. Venus y Mercurio concedieron a la fuente la virtud de cambiar de sexo a la persona que se bañara en sus aguas.

Las representaciones de Hermafrodito son muy frecuentes en la época helenistica, destacando una hermosa estatua perteneciente a la colección Borghese ${ }^{7}$ y actualmente en el Museo del Louvre, de la que Velázquez trajo un vaciado a nuestro pais.

Su valor simbólico y alegórico es ciertamente confuso. Federico Revilla ${ }^{8}$ recoge las teorias del exégeta Alexandre Fillere que considera

\footnotetext{
${ }^{5}$ Ovidıo, Metamorfosis. Madrid, Espasa-Calpe, 1986. Lib. IV, II, págs. 73-74.

${ }^{6}$ Op. cit., pág. 73.

Velazquez y lo velazqueño. Madrid, Dirección Gnral. de B. A.. 1960. págs. 147-148. BlanCo, A. y Lorente , M. Catálogo de la escultura. Museo del Prado. 1981, pág. 151

${ }^{8}$ Revilla, F., Diccionario de iconografia, voz "Hermafrodito". Madrid, Cátedra, 1990, pág. 183.
} 


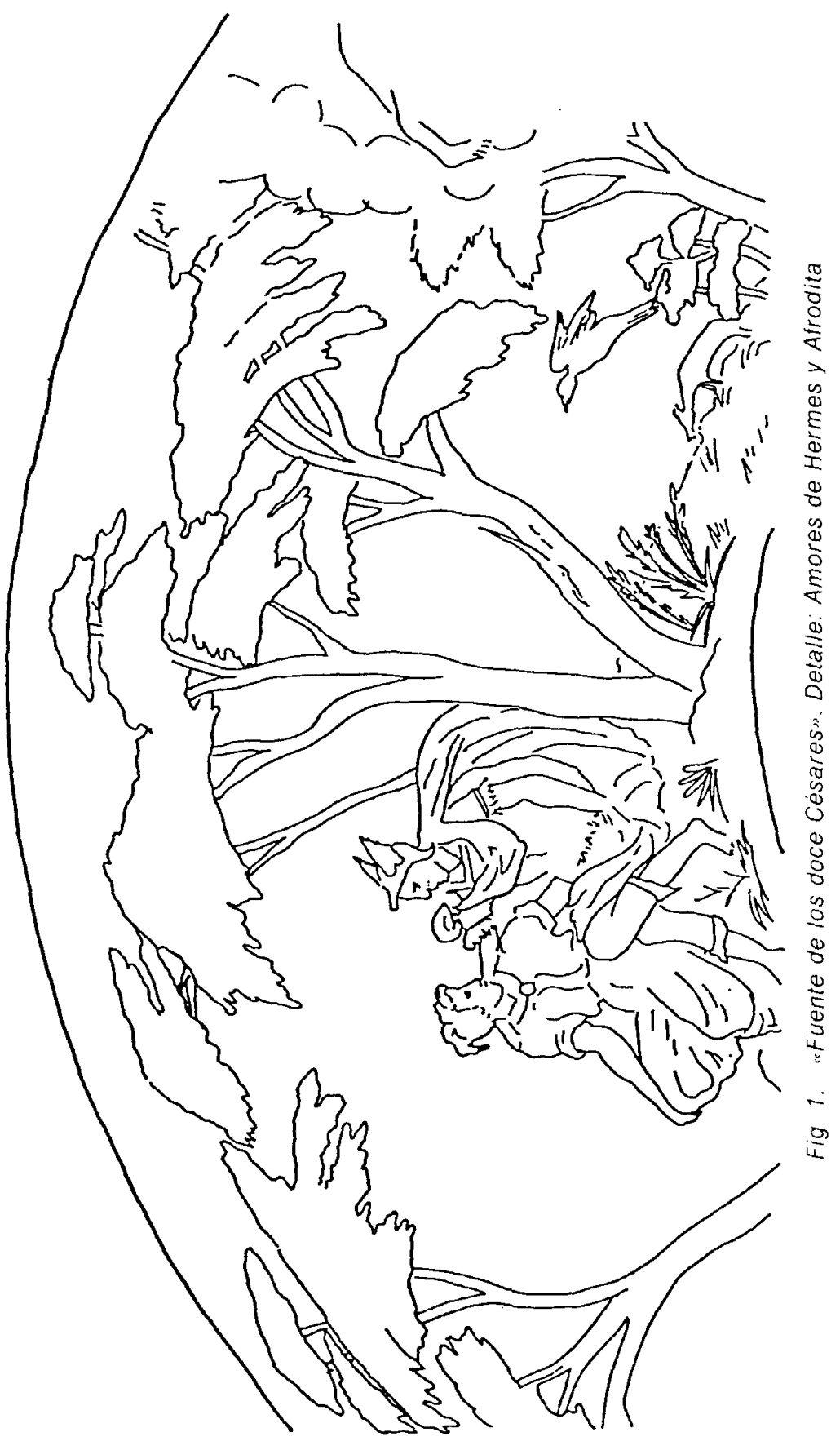




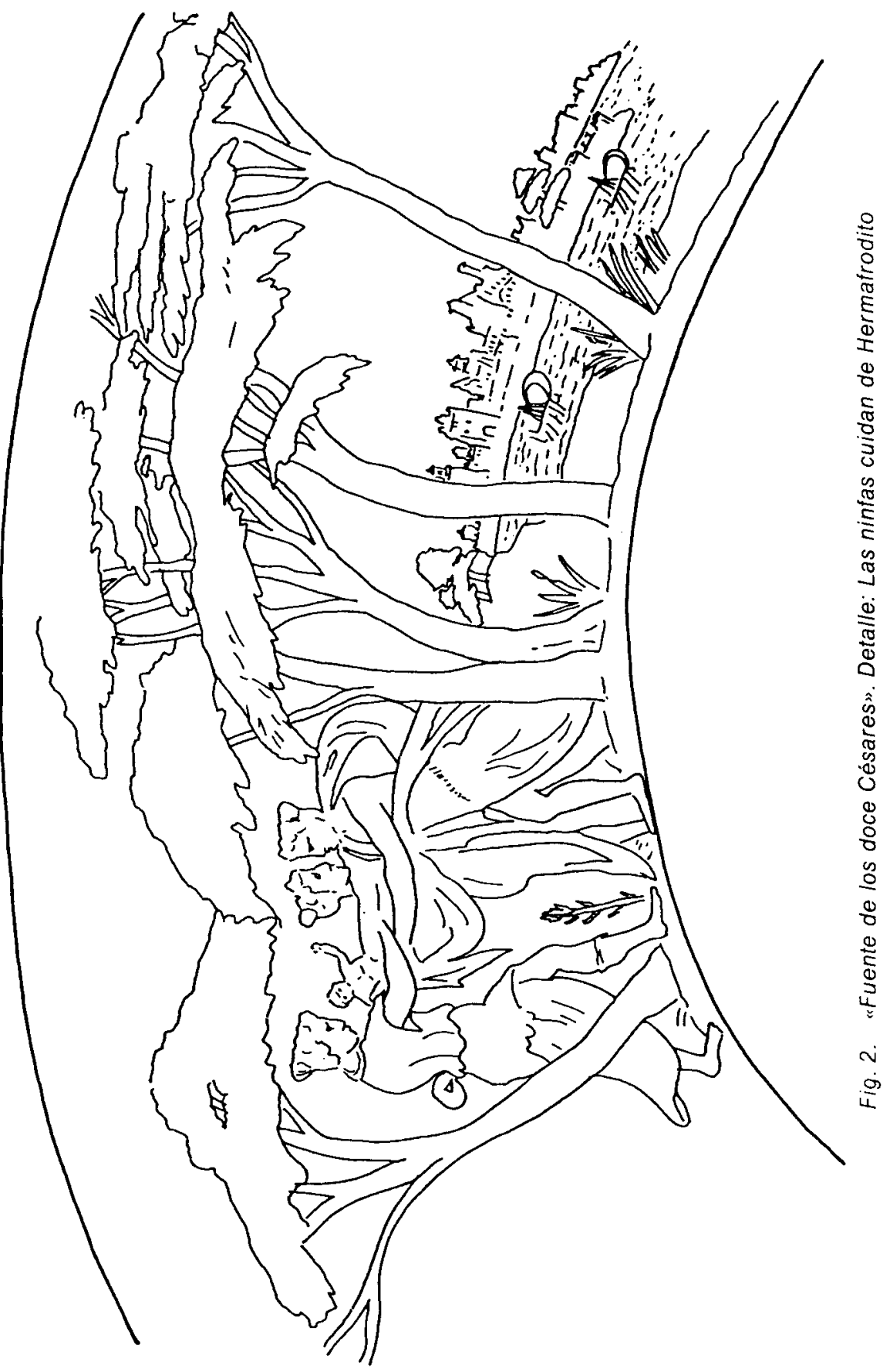




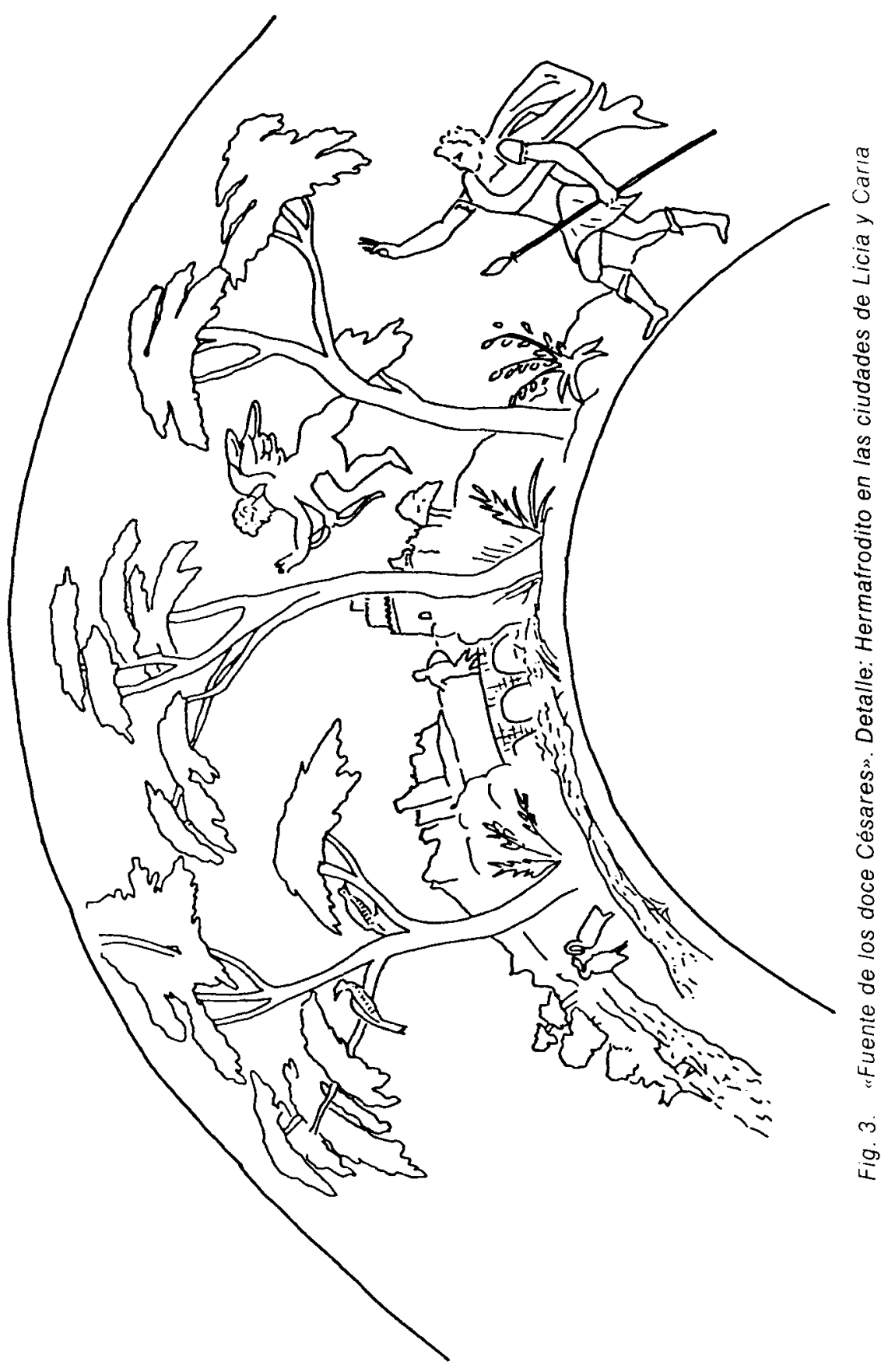


a Hermafrodito como simbolo de la Iglesia Católica en su voluntad de convertir y catequizar a los herejes. Manlio Brusatin ${ }^{9}$ cita a su vez a Michael Mayer que, en su "Symbola aureae mensae duodecim nationum" impreso en Frankfurt en 1617, ilustra con una representación de Hermafrodito, semejante a la de las "Alhajas", un simbolo asociado a la figura de San Alberto Magno con el lema "Omnes concordat in uno, qui est bifidus" (fig. 4).

La vinculación de la "Fuente de los doce Césares" con las "Metamorfosis" de Ovidio parece evidente, los artistas tienen en estas fábulas una

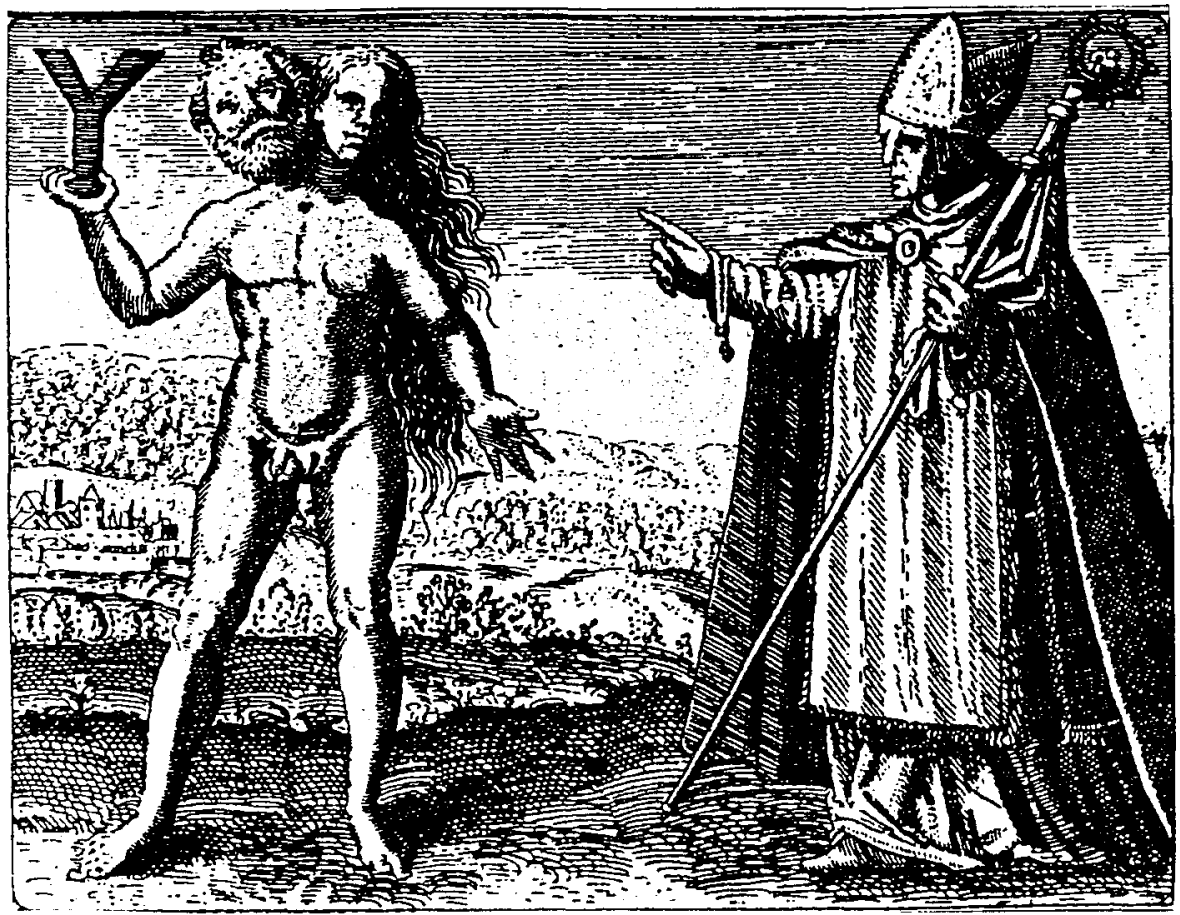

Fig. 4. "Omnes concordat in uno, qui est Bifidus". Simbolo vinculado a San Alberto Magno. Publicado por Michael MaYer en Symbola aureae mensae duodecim nationum, Frankfurt, 161?

${ }^{9}$ Brusatin, M., Historia de las imágenes. Madrid, Julio Ollero Editores, 1992, pie de la ilustración 23. 
inagotable fuente de asuntos que reproducir y que por obra de los eruditos de la época se enriquecen con valores simbólicos. Forman parte de alegorias, empresas y emblemas que ofrecen intrincados acertijos, cargados en numerosas ocasiones de aspectos moralizantes.

Este es el caso de la segunda pieza de nuestro estudio, una jarra de cristal de roca de la segunda mitad del siglo xvı cuyo asa está formada por una curiosa representación sirena de la que emerge el cuerpo de un joven ceñido en la cintura por racimos de uvas y hojas de parra (fig. 5). Angulo ${ }^{10}$ apunta que tal vez se trate de un Baco joven. El inventario de $1776{ }^{11}$ considera sirenas a estas dos figuras y las Observaciones de la Junta precisan:

"... Una de las vichas representa un joven y no una sirena...».

En las fuentes clásicas no se asocia al dios Baco con las sirenas. Esta divinidad, Dyonisos en griego, originario de Asia Menor representa el delirio mistico, el desenfreno y la locura producidos por el vino ${ }^{12}$.

Las sirenas son seres fantásticos; en su origen aves con cabeza femenina conocidas desde Homero hasta Ovidio ${ }^{13}$ están llenas de connotaciones negativas. Con el paso del tiempo cambiarán su fisonomía y acabarán representándose tal como todos las conocemos: un cuerpo de mujer acabado en cola de pez. Ellas atraian hacia las rocas a los marinos, que poseidos por sus voces morían inevitablemente estrellando sus barcos. Representan a la mujer que seduce, espiritu de la tierra en contraposición al del hombre que simboliza el cielo. La representación de la sirena-pez encuentra gran fortuna en el Renacimiento que la incluye en multitud de programas decorativos.

La unión de estas dos figuras nos lleva a pensar en un contenido simbólico de carácter moralizante que expresara los peligros del vino representados por Baco, y de los placeres encarnados en las sirenas ante los que sucumbe el hombre en estado de embriaguez (fig. 6). La emblemática renacentista y barroca ofrece numerosas alusiones a Baco y al vino, pero será Alciato ${ }^{14}$ el que dedique varios de sus “Emblemas", publicados en

10 Angulo, D., Catálogo..., pág. 122.

"Op. cit., pág. 231.

${ }^{12}$ Interesantes datos sobre el origen y el culto a Baco en: Dodos, E. R., Los griegos y 10 irracional. Madrid, Alianza Editorial, 1986, cap. III, págs. 71-90 y cap. VIII, apéndice I, págs. 251-260. EuriPIDes, Las bacantes. Madrid, C.S.I.C., 1982, págs. 25-92.

${ }^{13}$ Ovidio, Op. cit. Lib. V, III, pág. 97.

${ }^{14}$ Alciato, Emblemas. Madrid, Editora Nacional, 1975, emblemas 23, 24 y 25 


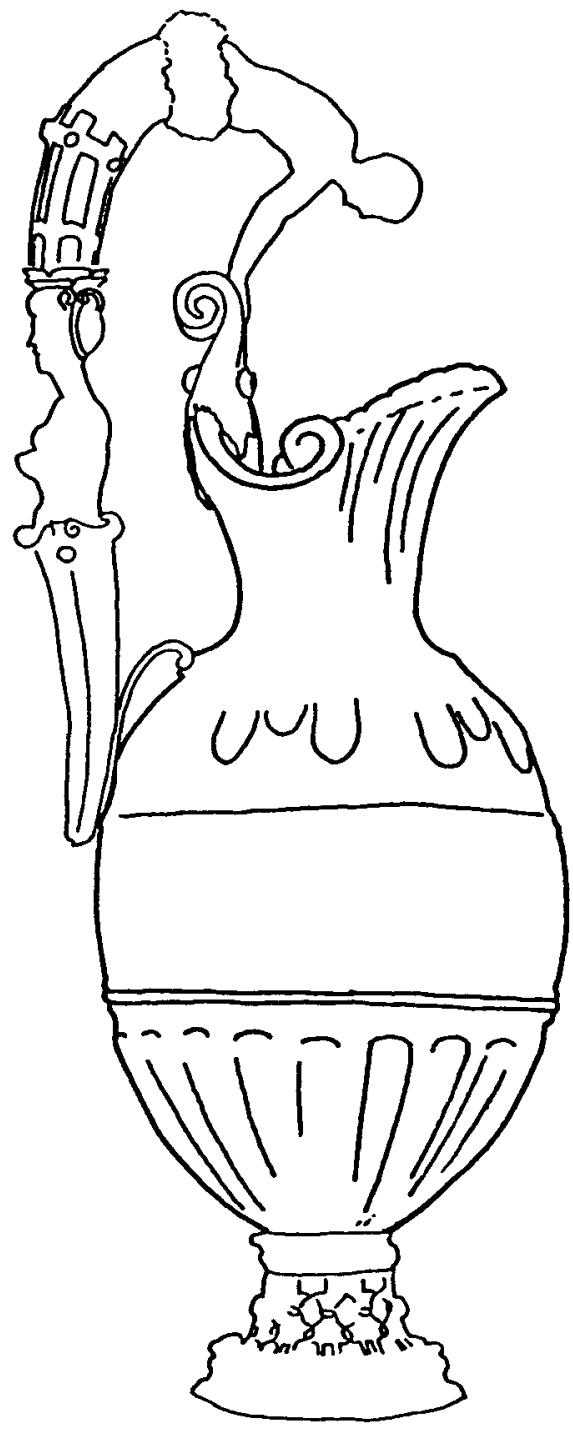

Fig. 5. «Jarra con sirenas en el asa» 


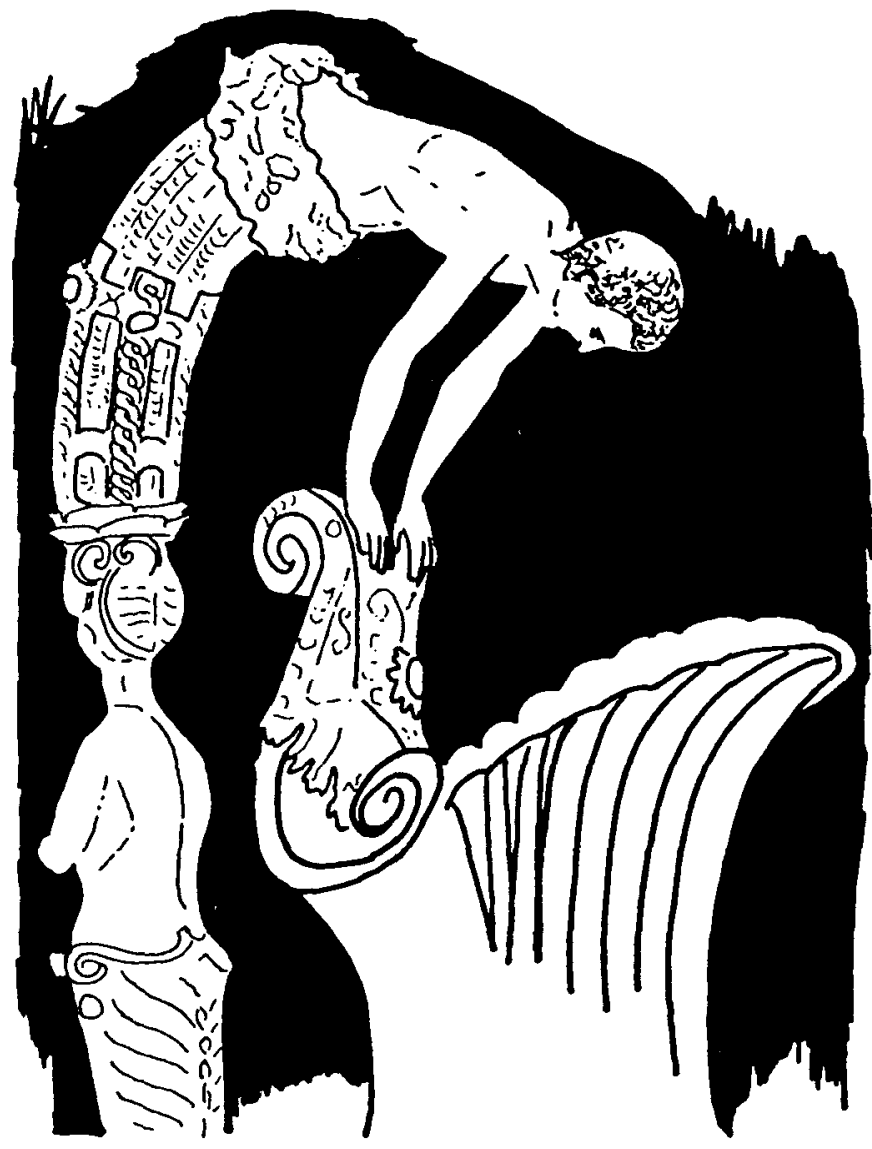

Fig. 6. "Jarra con sirenas en el asa". Detalle: Baco emerge de la cabeza de una sirena

1531, al vino en relación con la virtud y la prudencia. Concretamente el titulado "La estatua de Baco» da las claves para entender la representación de las "Alhajas". Recoge en forma de diálogo la conversación de un hombre que pregunta al dios sobre su naturaleza, a lo que éste responde:

«...- Quando mi padre me sacó teñido del vientre de mi madre, en agua fría me lavó, como estaba empolvorido.

De alli fue cuerdo quien la fuerza mia mezcló con agua, y quien me bebe puro abrasa sus entrañas a porfia. 
- Pues de mitigar eres tan duro dime, ¿por qué ley quieres ser mezclado para que quien te beba esté seguro?

- Un vaso de buen vino, ser aguado con doblada agua (por lo menos), quiere aqueste es el mezclar más moderado. Más aún, el que con tal ley me bebiere no llegue hasta un cuartillo, que si llega sea borracho y loco se requiere.

- Quan áspera y quan dura ley se alega: nuestras gargantas son de gran caida y dulcemente tu licor las riega.

- No hay quien no se agüe en esta vida...".

Esta descripción poética nos avisa del peligro del vino en estado puro e indica la mezcla de agua para mitigar sus efectos nocivos. Basándonos en esto, no es arriesgado pensar que las dos figuras de la jarra aludan a los líquidos que representan, Baco al vino y la sirena al agua, unidos como indica Alciato en el asa de una jarra cuya función seria, quizá, alojar la mixtura agradable e inofensiva de la que habla el poema ${ }^{15}$.

Del análisis de estos dos objetos deducimos una aplicación diferente de la mítologia en la decoración. Legitimada plásticamente desde la Antigüedad clásica y reordenada con nuevos contenidos en el Renacimiento, en un contexto cultural y artístico fascinado por unos dioses que gozan de una "humanidad", tan literaria como verosimil.

\section{RESUMEN}

La colección de vasos ornamentales denominada "Alhajas del Delfin" aparece decorada en muchas de sus piezas con asuntos extraidos de la mitologia clásica. Se analizan dos objetos cuyo tratamiento iconográfico es excepcional. El primero, "La fuente de los doce Césares", describe un asunto extraido fielmente de la fuente clásica: "Las metamorfosis" de Ovidio; el segundo, "Jarra con sirenas en el asa", presenta un contenido alegórico obtenido de la literatura artística del siglo xvI: "Los emblemas" de Alciato. Ambos están protagonizados por personajes míticos y se suman a las corrientes artísticas y eruditas post-renacentistas, fascinadas por las posibilidades estéticas, filosóficas y literarias que ofrece el Olimpo y sus "habitantes".

1s La costumbre de mezclar el agua con el vino para mitigar sus efectos, la heredamos del mundo clásico. En la Edad Media sirve como pretexto para la representación iconográfica de la templanza, asi la vemos pintada en el trono del Santo Domingo de Silos de Bartolomé Bermejo. 
